\title{
PENGARUH PSIKOEDUKASI TERHADAP TINGKAT PENGETAHUAN TENTANG STIGMA GANGGUAN JIWA
}

\author{
Ahmad Guntur Alfianto ${ }^{1)}$, Frengki Apriyanto ${ }^{2)}$, Maltri Diana ${ }^{3)}$ \\ Program Studi Ilmu Keperawatan, Stikes Widyagama Husada Malang \\ email: 15589ahmadguntur@gmail.com
}

\begin{abstract}
Abstrak
Stigma merupakan label negatif yang melekat pada diri seseorang yang diberikan oleh masyarakat dan dipengaruhi oleh lingkungan sekitar. Psikoedukasi dapat menjadi salah satu terapi yang dapat digunakan untuk menurunkan stigma dan diskriminasi terhadap orang dengan gangguan jiwa. Tujuan penelitian ini adalah menganalisis pengaruh psikoedukasi terhadap tingkat pengetahuan masyarakat tentang stigma gangguan jiwa diKecamatan Bululawang. Penelitian ini menggunakan jenis penelitian kuantitatif dengan desain quasi experimental research dengan rancangan Non-Randomize Control Group dengan menggunakan teknik Purposive Sampling dengan jumlah sampel sebanyak 100 resonden. Uji statistik yang digunakan dalam penelitian ini adalah uji $t$ dependent. Instrumen dalam penelitian ini berupa kuesioner Knowledge About Mental Illness. Hasil penelitiannya adalah Kelompok psikoedukasi keluarga $(2,66)$ dan kelompok kontrol $(0,222)$ memiliki nilai selilsih perbedaan terhadap tingkat pengetahuan tentang stigma gangguan jiwa di masyarakat Kecamatan Bululawang Kabupaten Malang. Sehingga terdapat pengaruh pada kelompok psikoedukasi keluarga $(p<0,05)$ dan tidak terdapat pengaruh pada kelompok kontrol $(p>0,05)$. Kesimpulan penelitian ini adalah Ada pengaruh psikoedukasi terhadap pengetahuan masyarakat tentang stigma gangguan jiwa.
\end{abstract}

Kata kunci : psikoedukasi, pengetahuan, stigma gangguan jiwa

\begin{abstract}
Stigma is a negative label attached to someone that is given by the community and influenced by the surrounding. Psychoeducation can be one of the therapies that can be used to reduce stigma and discrimination against people with mental disorders. The aim of this study to analyze the effect of psychoeducation on public knowledge about mental disorders stigma in Bululawang. This study used quantitative research with quasi experimental research design with Non-Randomize Control Group design using purposive sampling technique with a total sample of 100 respondents. The statistical test used in this study was the t dependent test. The instrument in this study is a Knowledge About Mental Illness questionnaire. The results of the study were the family psychoeducation group (2.66) and the control group (0.222) having a value as different as the difference in the level of knowledge about mental disorders stigma in Bululawang. So that there was an effect on the family psychoeducation group $(p<0.05)$ and there was no effect on the control group ( $p>0.05$ ). The conclusion of this study is that there is an influence of psychoeducation on public knowledge about the stigma of mental disorders.
\end{abstract}

Keywords : psychoeducation, knowledge, stigma of mental disorders

\section{PENDAHULUAN}

Prevalensi kejadian gangguan jiwa di dunia pada tahun 2013 mencapai 450 juta orang dengan gangguan jiwa(WHO, 2013). Hasil Riset Kesehatan Dasar tahun 2013 di Indonesia menunjukkan bahwa gangguan jiwa mental emosional yang ditunjukkan dengan gejala-gejala depresi dan kecemasan adalah sebesar 6\% untuk usia 15 tahun ke atas atau sekitar 14 juta orang. Sedangkan, prevalensi gangguan jiwa berat, seperti schizophrenia adalah 1,7 per 1000 penduduk atau sekitar 400.000 orang.

Jawa Timur merupakan provinsi di Indonesia yang menduduki peringkat enam dengan masalah ganggun jiwa berat. 
Sedangkan gangguan mental emosional Jawa Timur berada pada urutan ke 5 dengan 6,5\%. Malang merupakan salah satu kabupaten di provinsi Jawa Timur yang memiliki urutan lima dengan kejadian gangguan jiwa berat sebesar 11,5 per 1000 penduduk. Gangguan jiwa emosional menduduki urutan ke tiga kabupaten dan kota di provinsi Jawa Timur yaitu 11,5 per 1000 penduduk (Badan Penelitian dan Pengembangan Kesehatan Kementrian kesehatan Indonesia, 2013).

Seseorang yang mengalami ganggun jiwa di masyarakat akan memiliki perilaku yang menyimpang dan serta mengalami distorsi emosi (Stuart \& Lararia, 2013). Perubahan perilaku pada seseorang dengan gangguan jiwa berat meyebabkan penolakan di masyarakat karena muncul persepsi tentang stigma negatif terhadap seseorang dengan gangguan jiwa (Work, 2011). Masyarakat juga beranggapan seseorang dengan gangguan jiwa berat sangat berbahaya, agresif serta rawan melakukan tindakan kekerasan, sehingga masyarakat lebih mengasingkan dan menolak jika di lingkunganya terdapat seseorang dengan ganggun jiwa (Ivezi, Sesar, \& Muẑini, 2017).

Berdasarkan studi pendahuluan yang telah di lakukan pada April 2018 jumlah orang dengan gangguan jiwa (ODGJ) di Kecamatan Bululawang adalah 170 ODGJ, yang terbagi dalam 14 desa. Desa yang paling banyak ODGJ yaitu desa Sukonolo 32 orang, desa Sudimoro 17 orang, desa Wadanpuro 16 orang, desa Lumbangsari 14 orang, dan desa Sengrong 13 orang. Berdasarkan studi pendahuluan pada 10 orang masyarakat di Kecamatan Bululawang 9 orang diantaranya masih menolak keberadaan ODGJ dan mengatakan takut terhadap orang dengan gangguan jiwa karena dianggap berbahaya.

Stigma terhadap gangguan jiwa dipengaruhi oleh ketidak tahuan, prasangka serta perilaku diskriminasi terhadap sseseorang dengan gangguan jiwa (Mosanya, Adelufosi, Olaolu, Ogunwale, \& Adebayo, 2014). Persepsi masyarakat tentang gangguan jiwa dapat merusak interakasi sosial di masyarakat hingga kasus terburuk adalah terjadinya bunuh diri pada keluarga ODGJ ataupun individu tersebut $(\mathrm{Mu}, 2013)$. Sehingga perlu adanya pencegahan sedini mungkin terhadap masalah gangun jiwa dimasyarakat (Varcarolis, 2010).

Upaya pencegahan tentang stigma gangguan jiwa salah satunya pemberian pesikoedukasi. Psioedukasi adalah sebuah tindakan modalitas yang di sampaikan oleh profesional, yang mengintegrasikan dan mensinergiskan antara psikoterapi dan intervensi edukasi. Psikoedukasi merupakan pengembangan dan pemberian informasi dalam bentuk pendidikan masyarakat mengenai informasi yang berkaitan dengan psikologi populer/sederhana atau informasi lain yang mempengaruhi kesejahteraan psikososial masyarakat (Stuart, 2013).

Berdasarkan penelitian yang dilakukan oleh (Choe et al., 2016) pemberian psikoedukasi kepada pasien scizofrenia dan scizoafektif ditemukan bahwa psikoedukasi meningkatkan pengetahuan dan pemahaman pasien tentang penyakit dan meningkatan kepatuhan dalam kansumsi obat. Psikoedukasi sangat efektif meningkatkan harga diri pasien dan juga memfasilitasi komunikasi antara pasien dan perawat.

Pengetahuan masyarakat tentang gangguan jiwa masih kurang mendapatkan perhatian khusus oleh perawat khususnya perawat kesehatan jiwa di komunitas, sehingga dapat memperburuk dalam memberikan layanan asuhan keperawatan di masyarakat. Oleh sebab, itu pada penelitian saat ini akan merubah pemgetahuan tentang stigma gangguan jiwa di masyarakat khususnya di kecamatan Bululawang dengan pemberian intervensi psikoedukasi. Tujuan penelitian ini adalah menganalisis pengaruh psikoedukasi terhadap pengetahuan tentang stigma gangguan jiwa di Masyarakat Kecamatan Bululawang Kabupaten Malang

\section{METODE PENELITIAN}

Penelitian yang digunakan adalah penelitian eksperimen dengan pendekatan eksperimen semu (quasi experimental research). Rancangan eksperimen semu yang digunakan adalah Non-Randomize Control Group Pretest-Posttest Design (Lapau, Buchari, 2013). Besar sampel untuk penelitian ini adalah 100 responden yang memiliki tetangga yang mengalami gangguan jiwa di Kecamatan Bululawang Kabupaten Malang.

Instrumen yang digunakan dalam penelitian yaitu kuesioner Knowledge About Mental Illness untuk mengukur pengetahuan (Wahl et al., 2012a). Kuesioner ini berjumlah 17 soal dengan pilihan jawaban sangat tidak setuju (STT), tidak setuju (TS), Setuju (S), sangat setuju (ST) (Wahl et al, 2012) dengan 
skala interval dan hasil ukurnya 0-51. Uji validitas dan reliabilitas dilakukan di Kecamatan Bantur dengan jumlah sampel sebanyak 30 responden. Kuesioner yang digunakan yaitu kuesioner knowledge about mental iillness untuk mengukur tingkat pengetahuan masyarakat berjumlah 17 pertanyaan. Uji validitas didapatkan nilai $r_{\text {hitung }}$ $0,502-0,715$ yang artinya lebih besar dari $r_{\text {tabel }}$ yaitu 0,361 dan nilai reliabilitas adalah 0,911

Teknik pengumpulan data dilakukan pada bulan Juli sampai September. Penelitian ini menggunakan teknik pengumpulan jawaban pre test dan post testpada kelompok intervensi dan kelompok kontrol. Kelompok intervensi diberikan psikoedukasi selama 5 sesi yaitu:

1. Sesi satu: identifikasi masalah yang dihadapi oleh masyarakat melalui pengkajian

2. Sesi dua: manajemen beban yang dialami oleh masyarakat

3. Sesi tiga: manajemen kecemasan

4. Sesi keempat: edukasi kepada masyarakat

5. Sesi kelima: pemberdayaan kepada masyarakat.

Frekuensi pemberian psikoedukasi pada setiap responden selama 5 sesi. Setiap kali sesi dilakukan intervensi selama 45-60 menit, sedangkan untuk kelompok kontrol diberikan dalam waktu satu kali pertemuan dan lamanya pemberian pendidikan kesehatan pada kelompok kontrol kurang lebih antra 45-60 menit. Media yang digunakan pada penelitian ini adalah untuk kelompok psikoedukasi menggunakan lembar kerja tentang psikoedukasi yang sudah disediakan oleh peneliti dan peneliti juga menggunakan modul psikoedukasi stigma gangguan jiwa. Media pendukung menggunakan lembar balik dan leafet berisi tentang stigam gangguan jiwa, manajemen cemas, manjemen beban serta pemberdayaan di komunitas bagi masyarakat yang berada di lingkungan dengan tentangga yang mengalami gangguan jiwa. kelompok kontrol menggunakan media lembar balik dan leaflet.

Analisis data menggunakan software Statistikal Package for the Social Sciens 16 (SPSS 16). Uji statistik yang digunakan adalah uji $t$ dependent test. Confidenceinterval (CI) yang digunakan adalah 95\%. Uji homogenitas dan uji normalitas data dilakukan terlebih dahulu sebelum dilakukan analisa data. Data dikatakan homogen jika hasil uji homogenitas didapatkan nilai $p<0,05$. Data dikatakan normal apabila hasil analisis Shapiro-Wilk (subjek/data < 50) dengan nilai sing lebih dari 0,05 untuk distribusi normal dan nilai probabilitas (nilai $p$ ) $<0,05$.

Persetujuan etik telah didapatkan dari Komisi etik penelitian kesehatan di Fakultas Ilmu Kesehatan Universitas Muhammadiyah Malang dengan nomer etik penelitian E.5.a/256/KEPK-UMM/VIII/2018.

\section{HASIL DAN PEMBAHASAN}

Tabel 1. Distribusi responden berdasarkan usia, jenis kelamin, pendidikan dan pekerjaan di Kecamatan Bululawang Kabupaten Malang

\begin{tabular}{cccc}
\hline \multirow{2}{*}{$\begin{array}{c}\text { Variabel } \\
\text { karakteristik }\end{array}$} & \multicolumn{3}{c}{ Kelompok psikoedukasi dan kontrol } \\
\cline { 2 - 4 } & Kategori & Frekuensi (n) & Persen (\%) \\
\hline \multirow{2}{*}{ Usia } & 26-35 Tahun & 32 & 27,1 \\
& 36-45 Tahun & 68 & 72,9 \\
Jenis kelamin & Laki-laki & 14 & 28,8 \\
& Perempuan & 86 & 71,2 \\
& SD & 2 & 1,7 \\
Pendidikan & SMP & 30 & 27,1 \\
& SMA & 50 & 44,1 \\
& Perguruan Tinggi & 16 & 22 \\
& Tidak bekerja & 57 & 48,3 \\
Pekerjaan & Petani, Buruh serabutan & 21 & 17,8 \\
& Wiraswasta & 10 & 14,4 \\
& Swasta & 10 & 14,4 \\
& PNS & 2 & 5,1 \\
\hline
\end{tabular}


Tahapan analisis data pada penelitian ini menggunakan uji homogenitas dan uji normalitas data. Hasil Uji homogenitas dengan menggunkana uji levine adalah pengetahuan pretest sebesar 0,219 . Sehingga kedua kelompok tersebut memiliki nilai varian yang sama (homogen).

Hasil uji normalitas data menggunakan Analisis Kolmogorov Sminov dengan hasil Variabel pengetahuan pada kelompok psikoedukasi adalah pretest $(0,200)$ postets $(0,200)$ sedangkan pada kelompok kontrol pretest $(0,200)$ dan postetst $(0,200)$ sehingga dapat disumpulkan bahwa kedua variabel tersebut berdistribusi normal.

Tabel 2. Perbedaan Psikoedekasi Terhadap Tingkat Pengetahuan tentang Stigma Gangguan Jiwa di Masyarakat Kecamatan Bululawang Kabupaten Malang PJK $(n=100)$

\begin{tabular}{lrcc}
\hline Variabel & Mean & $\mathrm{t}$ & $p$ \\
\hline \multicolumn{4}{c}{ Pengetahuan } \\
psikoedukasi & & \\
pretest & 25,28 & 2,66 & 0,003 \\
posttest & 27,94 & & \\
\multicolumn{2}{r}{ Pengetahuan kontrol } \\
pretest & 24,56 & 0,222 & 0,625 \\
posttest & 24,78 & & \\
\hline
\end{tabular}

Total responden pada penelitian ini adalah 100 responden yang terbagi menjadi 2 kelompok yaitu 50 orang untuk kelompok psikoedukasi dan 50 orang untuk kelompok kontrol. Usia, jenis kelamin, Pendidikan dan status pekerjaan pada kelompok psikoedukasi dan kelompok kontrol dapat dilihat pada tabel 1 .

Kelompok psikoedukasi keluarga $(2,66)$ dan kelompok kontrol $(0,222)$ memiliki nilai selisih perbedaan terhadap tingkat pengetahuan tentang stigma gangguan jiwa di masyarakat Kecamatan Bululawang Kabupaten Malang. Sehingga terdapat pengaruh pada kelompok psikoedukasi keluarga $(p<0,05)$ dan tidak terdapat pengaruh pada kelompok kontrol $(p>0,05)$ lihat pada tabel 2.

Pengetahuan adalah merupakan hasil "tahu" dan ini terjadi setelah orang melakukan penginderaan terhadap suatu objek tertentu. Penginderaan terhadap objek terjadi melalui panca indra manusia yakni indra penglihatan, pendengaran, penciuman, rasa dan raba dengan sendiri. Pada waktu penginderaan sampai menghasilkan pengetahuan tersebut sangat dipengaruhi oleh intensitas perhatian persepsi terhadap obyek (Notoatmodjo, 2012).

Pengetahuan seseorang tentang gangguan jiwa mengandung dua aspek yaitu aspek positif dan aspek negatif. Kedua aspek ini yang akan menentukan sikap seseorang, semakin banyak aspek positif dan objek yang diketahui, maka akan menimbulkan sikap makin positif terhadap objek tertentu. Sikap masyarakat terhadap pasien gangguan jiwa adalah menerima, mengucilkan, membicarakan dan memandang pasien berbeda dengan masyarakat (Setiawati, 2012). Hernandez Arroyo et al., (2015) menyebutkan bahwa semakin tinggi pengetahuan seseorang mengenai ganggguan jiwa maka level toleransi orang tersebut terhadap pasien gangguan jiwa pun semakin tinggi.

Kurangnya pengetahuan masyarakat tentang gangguan jiwa membuat masyarakat membentuk stigma yang buruk terhadap orang dengan gangguan jiwa (Parcesepe and Cabassa, 2013). Berdasarkan hasil penelitian stigma yang kurang ini membuat masyarakat akhirnya takut terhadap orang dengan gangguan jiwa dan pada akhirnya terbentuk sikap diskriminasi kepada orang dengan gangguan jiwa seperti menghindar, mengusir, mengucilkan dan yang paling parah yaitu dipasung (Brohan et al., 2011). Psikoedukasi sangat bermanfaat untuk mencegah terjadinya kekambuhan penyakit, menurunkan stigma, membantu ODGJ untuk memiliki hubungan sosial yang lebih baik serta mengurangi depresi dan kecemasan. Selain itu dalam penelitian (Ivezi, Sesar and Muẑini, 2017) psikoedukasi juga sangat membantu dalam perubahan stigma diri dan pemulihan dari orang yang mengalami gangguan

\section{KESIMPULAN DAN SARAN}

Berdasarkan penelitian tersebut dapat disimpulkan bahwa ada pengaruh psikoedukasi terhadap tingkat pengetahuan tentang stigma gangguan jiwa di Kecamatan Bululawang. Sehingga saran pada penelitian ini adalah psikoedukasi dapat digunakan sebagai upaya pencegahan dan pemberdayaan masyarakat terhadap stigma gangguan jiwa dan sebagai upaya layanan gerakan masyarakat hidup sehat. 


\section{REFERENSI}

Badan Penelitian dan Pengembangan Kesehatan Kementrian kesehatan Indonesia (2013) 'Riset Kesehatan Dasar (RISKESDAS) 2013', Laporan Nasional 2013, pp. 1-384. doi: 1 Desember 2013.

Brohan, E. et al. (2011) 'Self-stigma, empowerment and perceived discrimination among people with bipolar disorder or depression in 13 European countries: The GAMIAN-Europe study', Journal of Affective Disorders. doi: 10.1016/j.jad.2010.09.001.

Choe, K. et al. (2016) 'Impact of Psychoeducation on Knowledge of and Attitude Toward Medications in Clients With Schizophrenia and Schizoaffective Disorders', Perspectives in Psychiatric Care, 52(2), pp. 113-119. doi: 10.1111/ppc.12106.

Hernandez Arroyo, L. et al. (2015) 'Stigma Related to Mental Illness in Medical Students From Madrid.', European Psychiatry. doi: 10.1016/S09249338(15)31440-1.

Ivezi, S. S., Sesar, M. A., \& Muziini, L. (2017) 'Effects of a group psychoeducation program on self-stigma, empowerment and perceived discrimination of persons with schizophrenia', Psychiatria Danubina, 29(1), pp. 66-73. doi: //doi.org/10.24869/psyd.2017.66.

Ivezi, S. S., Sesar, M. A. and Mużini, L. (2017) 'Effects of a group psychoeducation program on self-stigma, empowerment and perceived discrimination of persons with schizophrenia', Psychiatria Danubina, 29(1), pp. 66-73. doi: 10.24869/psyd.2017.66.

Lapau, Prof. Dr. Buchari, dr. M. (2013) 'Metodologi Penelitian Kesehatan', Jakarta: Rineka Cipta. doi: 10.3182/20130619-3-RU-3018.00554.

Mosanya, T. J., Adelufosi, A. O., Olaolu, T., Ogunwale, A., \& Adebayo, O. K. (2014) 'Self-stigma , quality of life and schizophrenia: An outpatient clinic survey in Nigeria'. doi: //doi.org/10.1177/0020764013491738.
$\mathrm{Mu}$, N. (2013) 'Public Stigma against People with Mental Illness in the Gilgel Gibe Field Research Center ( GGFRC ) in Southwest', 8(12). doi: https://doi.org/10.1371/journal.pone. 0082116.

Notoatmodjo, S. (2012) Promosi Kesehatan dan Perilaku Kesehatan, Jakarta: Rineka Cipta. doi: 10.1038/cmi.2015.110.

Parcesepe, A. M. and Cabassa, L. J. (2013) 'Public stigma of mental illness in the united states: A systematic literature review', Administration and Policy in Mental Health and Mental Health Services Research. doi: 10.1007/s10488-012-0430-z.

Setiawati, E. (2012) 'Studi Kualitatif tentang Sikap Keluarga terhadap Pasien Gangguan Jiwa di wilayah Kecamatan Sukoharj'. Available at: http://etd.eprints.ums.ac.id/20213/15 /02._Naskah_Publikasi.pdf.

Stuart G.W. \& Laraia M.T. (2013) Principle and practice of psychiatric nursing. Edition 10. St.Louis Missouri: Mosby Elsevier.

Varcarolis, E., M. (2010) Psychiatric Mental health nursing. Philadeplhia: Lippincot Williams and Wilkins.

Wahl, O. et al. (2012a) 'Knowledge and Attitudes About Mental Illness: A Survey of Middle School Students', Psychiatric Services, 63(7), pp. 649-654. doi: 10.1176/appi.ps.201100358.

Wahl, O. et al. (2012b) 'Knowledge and Attitudes About Mental Illness: A Survey of Middle School Students', Psychiatric Services, 63(7), pp. 649-654. doi: 10.1176/appi.ps.201100358.

WHO (2013) World Health Organization Zero Draft Global Mental Health Action Plan 2013-2020, WHO.

Work, M. S. (2011) Mental Health Stigma about Serious Mental Illness among MSW Students. Social Contact and At. 